"tarcsi" - 2007/8/10 - 11:53 - page $119-\# 1$

\title{
Learning and Knowledge: The results, lessons and consequences of a development experiment on establishing the concept of length and perimeter
}

\author{
MARGit TARCSI
}

Abstract. In the paper the four main stages of an experiment are described focusing on the question as to how much measuring the length and perimeter of various objects such as fences, buildings by old Hungarian units of measurements and standards contribute to the establishment of the concept of perimeter.

It has also been examined in what ways and to what extent the various forms of teaching such as frontal, group and pair and individual work contribute to the general knowledge, thinking, creativity and co-operation in this area.

It will also be shown to what extent folk tales, various activities and games have proved to be efficient in the teaching of the particular topic.

Every stage of the experiment was started and closed with a test in order to find out whether the development was successful and children managed to gain lasting knowledge in this particular area.

Key words and phrases: estimation, measurement, length, and perimeter.

ZDM Subject Classification: C02, E02, E12, E42, F92.

\section{Introduction}

\subsection{Problems in teaching geometry}

Teaching geometry is still based on the development of history, the pattern of Greek geometry, which evolved almost from the very beginning in terms of quantity, i.e. the from the geometry of measurement to the geometry of shapes. 


$$
\text { "tarcsi" - 2007/8/10 - 11:53 - page } 120-\# 2
$$

In my opinion, two approaches could be adopted in teaching geometry. A kind of historical introduction of measurements could be combined with dealing with shapes and these two approaches could meet when measuring the perimeter and the surface of shapes in plane.

In the geometry curriculum of lower primary, measurements are much more in the foreground than shapes and solids bodies, although children's mental development is rather in contrast with this approach, as the first geometric observations are rather qualitative than quantitative.

Since in teaching geometry in the first two classes we normally focus on measurements, thus that particular qualitative stage might be overlooked in which the transition in children's mind can happen from the concrete spatial operational level to level of abstract logical operations [10].

The other rather serious problem seems to be that in teaching measurements too many tasks are squeezed into the curriculum and the children are overwhelmed with all the tasks and measurements and transformation number, so it is almost a wonder that children are able to make a difference between them.

I am convinced that a lot more practical activity would be necessary in teaching measurements and we should also rely on much more on children's own knowledge gained in everyday life and their family. Thus the teaching material would seem to be more realistic to them and later they could much more make use of it in several areas.

In teaching measurements it is rather time consuming to arrange an activity based lesson, which is why teachers often omit this stage, although all of them are fully aware of the fact that acquiring concepts and knowledge is a lot easier through gaining tangible experience. Moreover the knowledge discovered by children themselves will be more lasting.

1.2. Teaching measurements, especially length, can have practical effect on teaching other subjects as well

- In teaching drawing the comparison of lengths, widths, sizes can be necessary for representations, although the subject rather focuses on the forms and modes of representation of figures.

- In PE lessons beside estimating and measuring lengths, directions can also play an important part, since in ball games the distance and direction should be rather exactly determined in order to get the ball into the right position. 


$$
\text { "tarcsi" - 2007/8/10 - 11:53 - page } 121-\# 3
$$

In the choice of the skipping ropes it is obviously the height of the body that makes a difference.

- In teaching technology units of length and the relations between them seem to be rather important in representation of solid bodies and spreading them in plane.

- In lower primary when teaching science in the observation of the growth of plants and animals, in making comparisons and being able to orientate on the map or the globe, not only the concept of length and the units of measurements are required but also interpreting the synonyms, and directions.

- In singing and music a new meaning is attached to measuring length, such as high, deep voice and low voice. Directions can be also important e.g. singing in deeper/high voice, although these terms can be seen as the changes of meaning of the words related to measuring length.

- In teaching mother tongue the interpretation of idioms related to lengths, such as high voice, deep voice, deep knowledge, deep breath, is fairly important, moreover becoming familiar with old Hungarian units of measurements in Hungarian folk tales can also be beneficial.

\section{Theory and methodology}

In teaching length as early as in the lower primary importance meaning will be attached to the following concepts and axioms. In teaching plane geometry the basic concepts are the point, the straight line and the distance. Plane is seen as the set of all the points, and certain subsets of the points of plane are considered as straight lines. It is also assumed that a non-negative number can be attached to any two points $A$ and $B$, the distance between $A$ and $B$.

I shall outline two basic axioms and the related mathematical and didactical references as follows.

\subsection{Axioms related to measuring length and knowledge related to them}

a) A section is broken into two sections by any of its inner point whose sum of lengths is equal to the length of the original section.

This axiom also implies the invariance of measuring lengths, described in detail by Piaget-Inhelder in Children's Psychology. "Concepts of preservation can be the psychological markers of the final establishment of a structure" [3, p. 89]. 


$$
\text { "tarcsi" - 2007/8/10 - 11:53 - page } 122-\# 4
$$

"At the pre-operational levels it is always the reactions focusing on perceptional or visual shapes that appear, which are followed at operational levels by reactions to identity based on reversibility either through inversion or reciprocity" [3, p. 91].

The concepts of invariance gradually evolve in the stage of concrete operations. According to our observations most children retain the concept of length by the age nine or ten. Various levels of invariance can be observed in the first four classes of primary school.

At the age of seven or eight children notice that if they see two identical bars or sections and one of them came about by translation, then their length is identical. Children rarely discover identity in rotation of figures because it represents a higher level, which appears at the age of eight or nine. In case of two identical broken lines of the same length and shape, where one of them was obtained from the other by some congruent transformation, the fact that they are equal is discovered by learners in case of translation, then later on in case of rotation and reflections. It is only by measuring that they are to compare a straight line and broken line of the same length.

Broken lines are derived from sections. A section is broken into two lines by an internal point, and the two new sections can also be broken into two lines, and continuing this procedure we get to the $A_{0} A_{1}, A_{1} A_{2}, A_{2} A_{3}, \ldots, A_{n-2} A_{n-1}$, $A_{n-1} A_{n}$ sections. These sections can be connected in the same direction and in this way the same $A_{0} A_{n}$ section can be regained, but they can also be connected in various directions and thus we get $A_{0} A_{1} \ldots A_{n}$ broken lines. If $A_{0}$ and $A_{n}$ points are identical, the broken line is closed, and the other way round is open. The straight line obtained from $n=1$ case is also identified as a broken line. The points where the sections of the broken line meet in due course are the joining point of the broken line. The length of the broken line is the sum of the length of sections of a broken line.

If a closed broken line shares no other points besides the prescribed joining points, then it is a polygon line. The length of the polygon line is the perimeter of the figure.

b) If a unit of length is given then at any half straight line with the origin

$A$ there is one and only one point $B$ for which $A B$ distance is a given positive real number.

This axiom connects measurements with functions, since only one and only one value belongs to an object to be measured by a given unit of measurement. Freudenthal in Didactical Phenomenology of Mathematical Structures [1] deals with various meanings of length, with the interpretation of length as function, 


$$
\text { "tarcsi" - 2007/8/10 - 11:53 - page } 123-\# 5
$$

with function operations and great emphasis is laid on the synonyms of length as well. The term length can be used both in space and time. Sometimes they overlap, because distance is determined in terms of time, e.g. it takes two hours to get from one village to another, ten minute walk from school, etc.

When we talk about a long object or the length of something length is synonym with words like width, height, thickness, distance, latitude and depth, which as a matter of fact are related to other dimensions or situations. E.g. we describe the sides of a rectangle 'lying' in plane as length and width, and in case of a 'standing' one we use the terms of width and height, however if the plane is turned by 90 degrees the terms length and height are used to describe the previously 'lying' rectangle's sides.

"We have turned the question 'What is length' towards an answer such as "length of ... is ...". This is a typically mathematical turn: transforming apparently isolated terms into symbols of functions" [1, p. 1].

"Length of ..." as a functional symbol: a function that talks about "long object" how long they are though not necessarily numerically specified, as in the length of this bed is $1.90 \mathrm{~m}$. Functional value may be vague: long, very long, short, very short, and so on $[1$, p. 2].

The second axiom also implies that providing the unit of length makes the function unambiguous, because if the unit of length is changed, then the number of length of the thing to be measured will also change. The comparison of sections, objects and things does not depend on the selection of unit of length.

In real life, when the length is given, the chosen length of unit has to be given as well (e.g. $5 \mathrm{~cm}, 5 \mathrm{~km}$ ), since the number will change in terms of this. This fact is made clear when we state that length is not just a number, but also a measurement unit of length dimension. In geometrical tasks it is quite often accepted that the length of unit is taken for granted and not even indicated when lengths are given.

2.2. The Pólya levels of understanding mathematical concepts (1965) can be used in establishing the concepts related to measurements

- Learners can understand the teaching material in the context of a lesson, if it can be connected to other concepts coming up during the lesson. E.g. the learner is able to connect the concept of centimetre to that of decimetre learned earlier. 


$$
\text { "tarcsi" - 2007/8/10 - 11:53 - page } 124-\# 6
$$

- In the given subject matter learners are able to find the relations i.e. they are familiar with the sizes of the units of length and their relationship to each other.

- A further stage of understanding is when learners are able to grasp the subject as a whole. Within measurements it is measuring length that has an outstanding role, as length is a basic quantity, and the units of measurement of area and volume are derived from it. A high level of abstraction and insight is needed to understand it.

- Cross-curricular aspects can further be enhanced in environment, PE, and technology lessons when measurements are applied.

- Discovering relations between knowledge gained at school and outside the classroom. One of the main aims of teaching mathematics is to make children able to apply their knowledge not only in routine situations, but they should also be able to use their knowledge in new problem situations and everyday situations.

Teachers should always bear in mind these levels of understanding and they should continually check children's level of knowledge before the next stage.

\subsection{The principle of realistic mathematics teaching and the constructivist theory of learning}

In our experiment ours basic principle is the principle of realistic mathematics teaching. The basic principle of realistic maths teaching is that in teaching concepts realistic situations are used as a starting point, a gradual progress is made towards the general (abstract) level. Not only real life situations but situations considered to be realistic by the learners can also be taken into account, as it happened while interpreting fairy tales.

According to constructivist theory of learning children not only store knowledge but also construct it. Children create theories, pictures, and models of reality, of the world. This is what happened when children used straws to make rectangles, squares, and triangles and in this creative activity children discovered the concept of triangle inequality. 


$$
\text { "tarcsi" - 2007/8/10 - 11:53 - page } 125-\# 7
$$

\section{Methodology of the Research}

\subsection{Research question}

The question to be answered was whether through estimations in their immediate environment, drawing open and closed broken lines and determining their length, children will be able to put the terms of length and perimeter into real context and to prepare their introduction through proper practice.

\subsection{Hypothesis}

We assume that plenty of experience in measurement and a lot of practice will improve

- the estimation skills;

- a better understanding of the concept of perimeter.

- Children will be able to use their knowledge in everyday life and find the relationship between the concept of area and perimeter.

\subsection{The Background of the Research}

The experiment, which took place in a class of István Bocskai Primary School (at present class 3. c), started in class 1 including class 3. There are twenty children in one class. The experiment started in 2004 spring. The school is at a housing estate, and the equipment and teaching methods are very much the same as anywhere in the region. The pupils can be described as a mixed ability group and their attitude to learning and mathematics is varied.

The experiment, which is still progress in class 4 , started in the second term of the first class, and ten or twelve afternoon sessions were held in the afternoon day care lessons by the author.

\subsection{Methods}

The sessions were taped (audio or video) and photographs were also taken. Occasionally worksheets were handed out in order to make children's work easier. In addition minutes were taken and we had conversions with some of the children.

The sessions were normally held during the whole term and at each stage of the experiment learners were tested at the beginning and at the end of the term. 


$$
\text { "tarcsi" - 2007/8/10 - 11:53 - page } 126-\# 8
$$

In the first stage children became familiar with concepts related to measuring length. First children were introduced to old Hungarian measurement units such fathom, span, step when reading Hungarian folk tales. After becoming fairly familiar with them and their relations and sizes and after having accomplished measurements with various instruments of measurements children gradually came to know standard measurement units, metre, decimetre and centimetre.

In the second stage no other measurement units of length were introduced to children, but we focused on the interrelations and their use as well as on the improvement of estimation skills and the preparation for the introduction of the concept of perimeter. Children drew open and closed broken lines on square grid sheets on paper, first following the instructions of the teacher, then on their own, and they determined the length of these lines. In this way, we intended to prepare them for the concept of perimeter. In-group work, children were asked to form squares and rectangles using strings of given length in the classroom. Then we made estimations and measurements outside the classroom, using various measurement units we measured the length, and width of the school, fence, etc.

At the beginning of the third stage of the experiment children filled in a test. After evaluating it and on the basis of experience gained so far children were interviewed at first in groups then in pairs in order to talk over problems and to show them that could also help each other to overcome their difficulties.

In order to make a clear difference between the concepts of perimeter and area children made polygons (triangles, squares and rectangles) from straws which they stringed on plastic lines. In this case we focused not only on accurate measurement but we also wanted the children to see that the sum of the length of the sides is actually identical with the length they measured as a total length before stringing the straws together, i.e. straightening the broken line the difference between the concepts of perimeter and surface was made quite clear.

In the fourth stage the concept of mile, kilometre and inch was presented after analysing them in folk tales and real life situations. Particular attention was devoted to improving estimation skills. Children determined measures in various dimensions. 


$$
\text { "tarcsi" - 2007/8/10 - 11:53 - page } 127-\# 9
$$

\section{Assessment of the results in stage four}

\subsection{Assessment of the preliminary and the delayed tests}

This test can be considered as a delayed test, since we dealt with these issues during the past three terms. Children were tested on $14^{\text {th }}$ November 2004. In the paper in the preliminary tests given out at the beginning of term four we intended to evaluate the problems related to the measurement of lengths and perimeters, as follow:

- the level of knowledge of units of measurement of length;

- to what extent are the estimations made in the immediate and wider environment were realistic;

- while estimating an object by various units of measurement, can children apply the interrelationship between the given units of measurement;

- measuring with a ruler, accuracy and mistakes;

- the awareness of drawing broken lines and determining their length;

- the level of abstraction of rectangle and its perimeter.

4.2. In the test handed out on $14^{\text {th }}$ November there were two tasks, which had been solved by the children previously

We wondered whether they would remember their earlier solutions or children who failed earlier would be able to solve them.

4.2.1. In the first task eight units of measurements had to be selected out of measurement units of various kinds

Except one child everybody dealt with the problem, and all the units of measurement selected by them were related to length. One girl did not follow the instructions to the end, therefore she picked only one unit of measurement, whereas the others at least four, which were mainly standard units of measurements. Actually 47 per cent of them found all the eight units of measurement of length. Most children had difficulties in using decimetre, as 32 percent of them did not consider it measurement of unit of length. The result in percentage is shown in Figure 1. 


$$
\text { "tarcsi" - 2007/8/10 - 11:53 - page } 128 \text { - \#10 }
$$

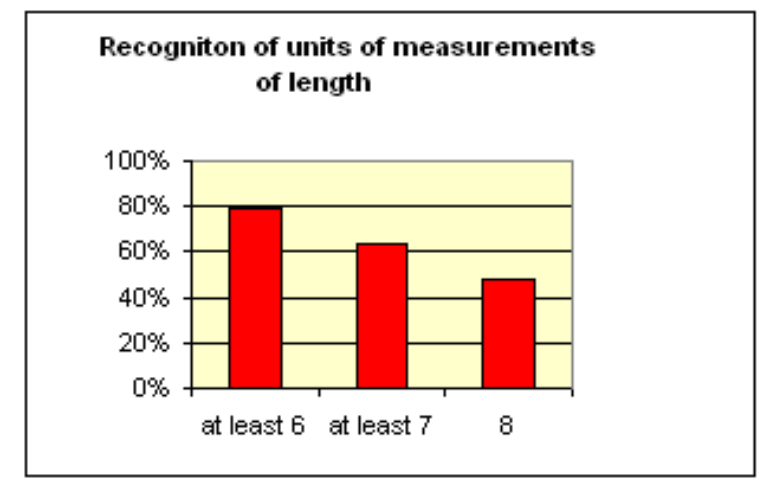

Figure 1

4.2.2. From the previous task the results of finding standard measurement units of length currently used standard units are shown in Figure 2

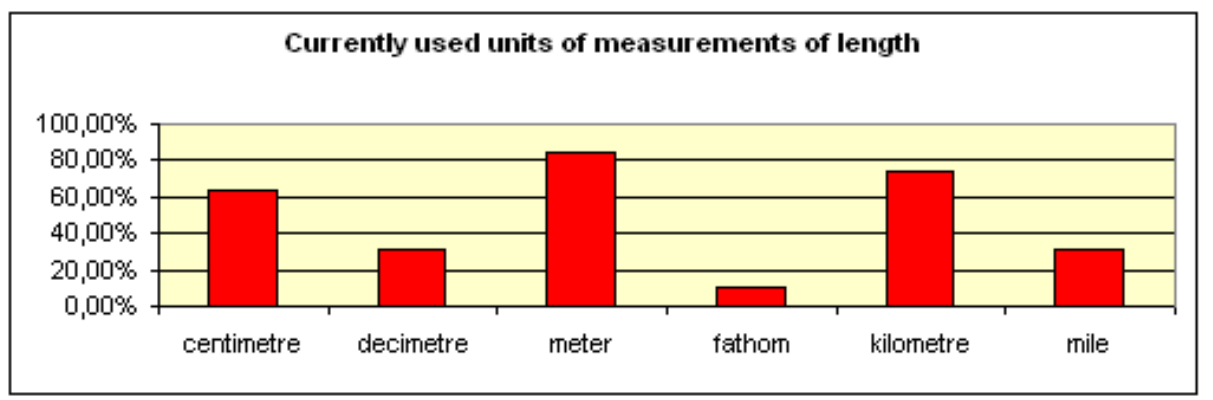

Figure 2

Some of the children probably ranked the mile ${ }^{1}$ among the standard units because it was previously mentioned that in the US and in Great Britain distances are measured by mile even these days. Only 32 percent of children consider decimetre as standard unit of measurement, probably because they hardly meet it in everyday life unlike négyszögöl (= 38.32 square feet), which is why they put it among standard units of measurement.

${ }^{1}$ The Hungarian mile $=8353$ metres, the English mile $=1609$ metres. 


$$
\text { "tarcsi" - 2007/8/10 - 11:53 - page } 129 \text { - \#11 }
$$

4.2.3. In the tasks checking the level of estimations children determined the writing surface of the desk by span, decimetre and centimetre, the length of the classroom by fathom, metre and ell as well as the length of fences of the school at Munkácsy Street and Víztorony Street respectively.

4.2.3.a The results of the first estimation are shown in Figure 3

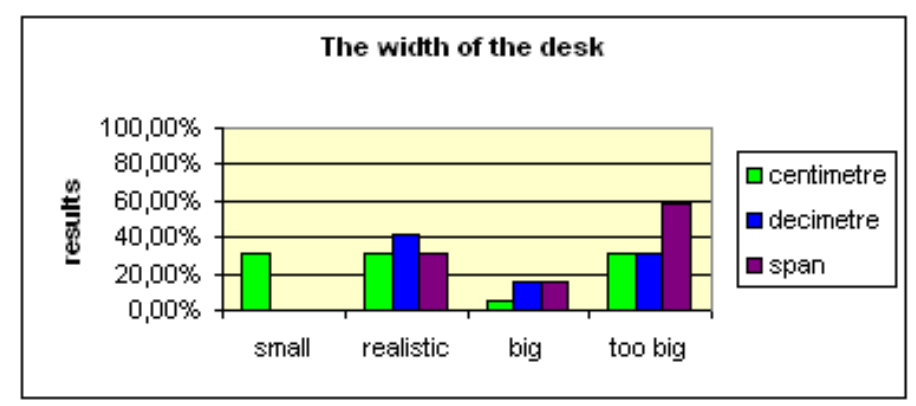

Figure 3

In this task children had problems with understanding, 57.9 percent of children took the width of the desk for the width of the line of the desks, what is actually the length of the surface of the desk. This misinterpretation was actually perceived by most children themselves after having a conversation with them after the test. The trouble with estimation by span was that some of them could not remember whether decimetre was shorter or longer than a span, which also happened in ordering objects. Half the children thought it was the span that was longer, whereas the other half believed it was the decimetre that was longer. The survey did not give an answer to the question if children were aware of the exact relationship between centimetre and decimetre. There was no evidence of the exact knowledge of the relationship between the two units of measurements in more than 50 percent of children. Four pupils transformed the estimation given in decimetre into centimetre, but most children made both estimations separately. It happened only in case of one pupil that the number of the estimations in decimetre and centimetre was identical, in case of the rest of the pupils the number of the centimetre was bigger than that of decimetre. Only 36.8 percent of the children were fully aware of the exact relationship between decimetre and centimetre. Estimation by decimetre was the most successful, probably because 


$$
\text { "tarcsi" - 2007/8/10 - 11:53 - page } 130-\# 12
$$

in establishing the concept an orange coloured bar of exactly one decimetre was used several times to measure the width and length of the desks.

4.2.3.b The results of estimations of the length of the classroom are shown in Figure 4

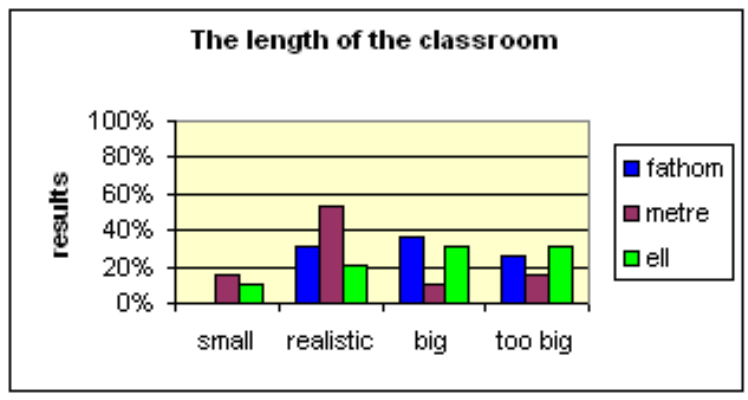

Figure 4

In 52.6 percent of children the number of fathom ${ }^{2}$ was smaller than that of the metre, and only 15.8 percent of children remembered the realistic relationship between fathom and metre, the rest believe the difference to be either too small or too big.

78.9 percent of the children considered the number of ell bigger than that of metre. Only 10 percent of the children took into consideration the proportion between the two numbers. When determining the number of ell ${ }^{3}$, the majority came up with a rather big value, which indicates what they had in mind was not really the size of the ell, but the fact that that ell is smaller than metre. The majority of objects were measured most of the time by metre and the efficiency of the practical activities is shown by the fact that the estimation of the width of the classroom by metre was the best.

4.2.3.c When estimating the length of streets, children relied on their memory, they had to recall their earlier estimations and measurements

According to children's earlier measurements:

${ }^{2} 1$ Hungarian fathom $=1.896$ metres.

${ }^{3} 1$ Hungarian ell $=0.78$ metre. 
The length of the fence in Munkácsy Street is about $100 \mathrm{~m}$ or 54 fathom or 136 ell.

The length of the fence in Víztorony Street is about $80 \mathrm{~m}$, or 43 fathom, or 100 ell.

The results of estimations are shown in Figure 5.
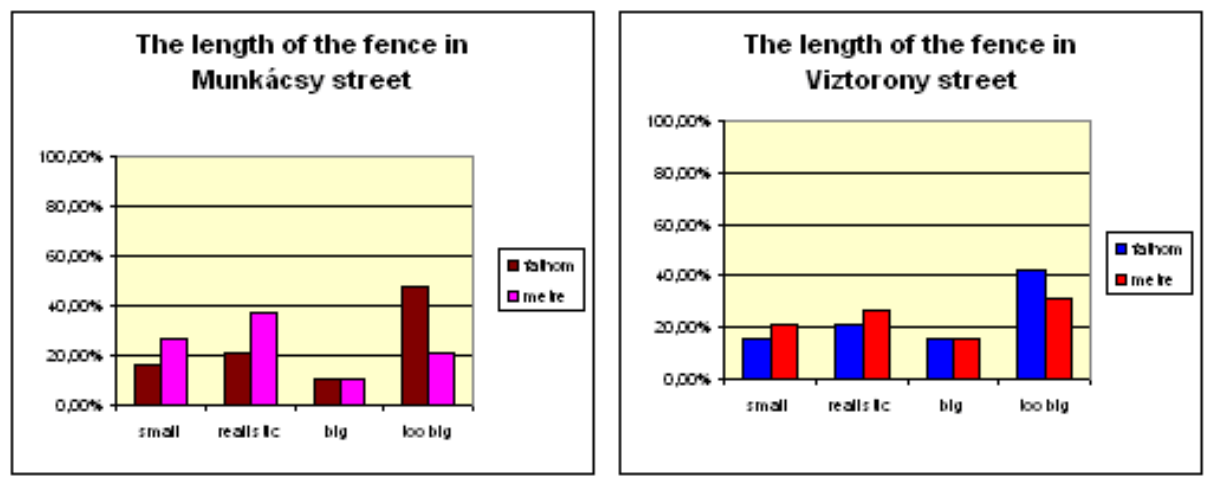

Figure 5

$47.4 \%$ of the children considered the fence in Munkácsy Street bigger, whereas $38.8 \%$ thought it was smaller, and 10.5 percent believed it was the same size as the fence in the other street.

In 57.9 percent of children the number of fathom was smaller than that of the metre, and 21 percent of them paid attention to the proportions as well. In 31.6 percent of children the difference between the two numbers was little but at least they took the size of the two numbers into consideration.

The estimations and measurements of the length of the fence at Munkácsy Street were made by the boys and in case of the fence at Víztorony Street were made by girls. Both teams reported on the results to the rest of the class. In case of the current estimations we have noticed that some of the children remembered only the results done by themselves, and the reports only superficially.

One girl estimated the length of the streets correctly, whereas fifty percent of the boys came up with realistic estimation.

The estimation of the three objects by standard units of measurements was done by 48.5 percent of the girls and 71 percent of the boys realistically. 


$$
\text { "tarcsi" - 2007/8/10 - 11:53 - page } 132 \text { - \#14 }
$$

\subsubsection{The pupils compared the sizes of two routes}

The drawing of the routes and the scale was given (one $\mathrm{cm}$ in the drawing is ten metres in reality), and the pupils were asked to determine the length of the broken lines with a ruler and the real length had to be deduced.

The length of the broken lines was given by centimetres by most children, and as it turned out in the conversations with them, some of them had not even read the instructions referring to real size. The original task, which required only determining the length of drawing, had already been done. Probably some of them remembered this and this is why they had not read the task to the end and they did not realize that that the condition was changed in the meantime. Earlier this task was done in pair and probably this is why it was more efficient, because when the pairs were set up pupils were chosen in way so that they could help each other in the measurements. Some children are still not able to start measurement from zero on the ruler, but luckily this is not typical, because even the very same pupil does not measure in the wrong way. Only one pupil had problems using the rule. The other problem was that not every section of the broken line was measured. The results are shown in Figure 6.

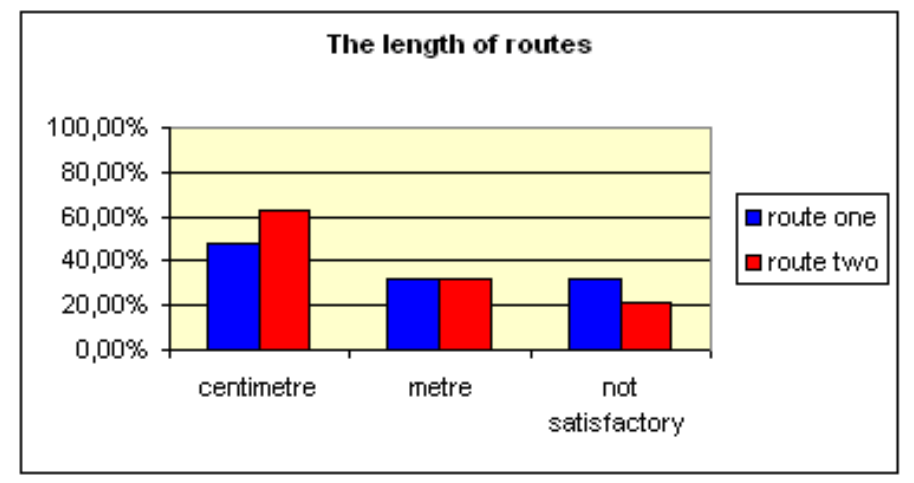

Figure 6

Route two consisted of fewer pieces; probably this is why they were able to determine its length better. The length of the routes in metre was determined by the same children, which made up 31.6 percent of the children. More than 60 percent of the children could determine exactly the length of a broken line consisting of five sections. 
4.2.5. Following written instructions children drew broken lines on a graph paper and they also had to determine the length of the lines

One of the tasks was e.g.

"Start from the upper left hand graph point. Move right 5, down 4, left 2, down 1. Determine the length of the line in centimetre or if you can in other units of measurement. How did you define the length of the line?"

We also wanted to see if they were able to determine the length by other units of measurements. In this task directions were also important. The task had been solved six months earlier, and the results of the two solutions can be seen in Figure 7.

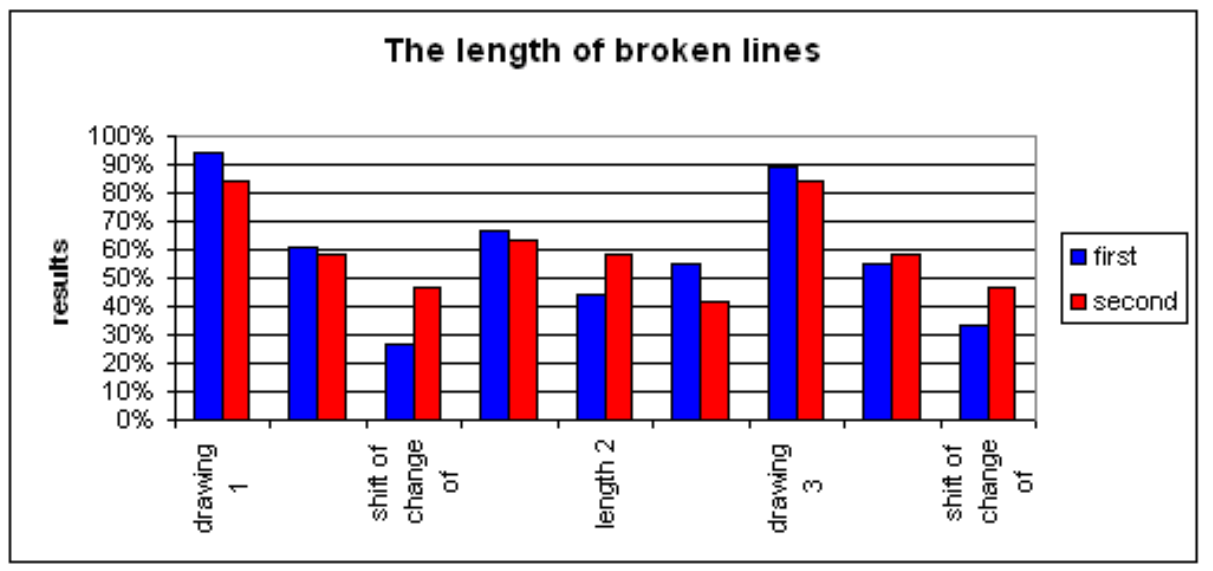

Figure 7

Children did not deal with this kind of tasks during the time between the two tests, so the results of the tests done later are quite good. Children made progress especially in putting down their explanations and they did their best to express themselves in complete sentences.

In the following answers were given to the question as to how they determined the particular lengths:

- I added the number of steps and I got the result.

- I added the upper numbers. (The pupil refers to the steps provided in the instruction.)

- I added the centimetres. 


$$
\text { "tarcsi" - 2007/8/10 - 11:53 - page } 134-\# 16
$$

- Square equals to one $\mathrm{cm}$.

- I determined it with a ruler.

- In such a way that in reality one $\mathrm{cm}$ is ten metres and this is how. (The pupil wanted to apply the requirement of the previous task.)

- I counted the grids.

The length of broken lines was determined by counting the grids eves in the autumn testing, but there was hardly a mistake in the directions in the counting.

4.2.6. The perimeter of four rectangles had to be determined and they measured and calculated values had to be arranged in a chart

The second of the rectangles was the 90-degree rotation of the first one, and the third and fourth were different from them, whose perimeter had to be determined. The results are shown in Figure 8.

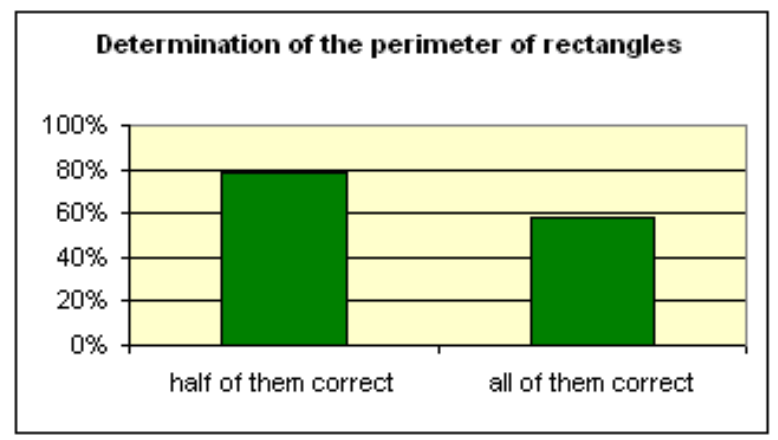

Figure 8

Inaccuracies still occurred in one third of the children. It was the deficiciency of the rulers used by the children that zero was not designated and this is why children were not quite sure where to start measurement, and some of the started it from $\mathrm{cm} 1$ or the plastic margin. Seventy-four percent of the children put unit of measurement next to the measuring number.

The following answers were given to the question: "What did you notice about the rectangle?"

- The perimeter of the first two and the third and fourth is the same.

- We got even numbers. 


$$
\text { "tarcsi" - 2007/8/10 - 11:53 - page } 135-\# 17
$$

- All of them can be described as squares: All of them have opposite sides and right angles.

- The first and second ones are of the same length, and so are the third and the fourth. The side of 1 . and 2. is the same, 3. is not and neither 4.

On the basis of this test further projects were designed, seeking the causes of problems, and insight of children's mind. Every lesson was documented in various ways, such as tape recordings, photographs, and worksheets.

4.3. Making use of the lessons drawn from the test in the sessions of stage four

The results of the tests were evaluated together with the children. The right solutions and the errors were analysed. By way of illustrations here are some excerpts from the lessons.

4.3.1. Conversations about units of measurements

Excerpts from the session of $21^{\text {st }}$ November 2005.

$\mathrm{T}$ : Why is it that few pupils regarded decimetre as a standard unit of measurement?

Ági Kovács: I don't really know if recently decimetre has been used.

Máté: It is still useful that decimetre is taught, because many people can transform e.g. let's say someone asks for $1000 \mathrm{~cm}$, but I'd rather say decimetre.

$\mathrm{T}$ : Almost as many children ranked mile among standard units of measurement as many of them did not rank decimetre among them. Why is it?

Barnus: The speed of some cars is measured in mile.

Máté: I think it's a good idea to know rare units of measurement, and I don't think it's a silly thing that the distance of something from here is eight miles.

$\mathrm{T}$ : In terms of British or Hungarian mile?

Máté: English is an international language.

Ági: In Britain it's not the kilometre but the mile is used.

$\mathrm{T}$ : In Britain kilometre is used in science, in everyday life mile; inch is also used in the US.

Máté: Now I remember in class two you told us to measure the size of the monitor. 


$$
\text { "tarcsi" - 2007/8/10 - 11:53 - page } 136 \text { - \#18 }
$$

Tamás: I think why they don't use kilometre is. . In Hungary it is used because the perimeter of Hungary can be measured in kilometre, but the perimeter of Britain is almost twice as much as much as that of Hungary.

Barnus: Hungarian mile is too big, which is why it is not used.

\subsubsection{Estimations}

$16^{\text {th }}$ November 2005.

In order to develop children's ability to estimate and to make them find the relationship between the units of measurement and number, various estimations and measurements were carried out. Moreover the children themselves invented newer ones so that they would find the sessions interesting and meaningful.

We measured the width of the classroom in ell and fathom. Standing behind each other one arm stretched, thus according to the number of children they could find out about how many ells are the widths of the classroom.

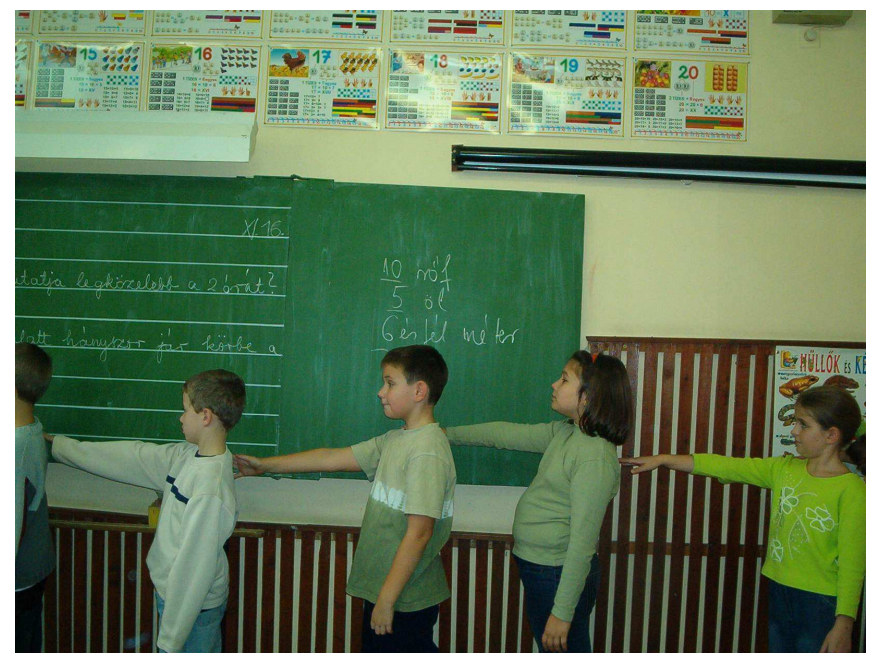

Picture 1

Máté: This is not quite right, because people also have width and it would also make about two ells if they stood next to each other. (He is a keen observer and his insight and creativity largely contributed to the experiment. He disagreed before starting the measurement, 


$$
\text { "tarcsi" - 2007/8/10 - 11:53 - page } 137 \text { - \#19 }
$$

because he noticed that the children did not put their hands on each others' shoulders but they stood at arm's lengths.)

Pisti: I think ten and a half. (Pisti's estimation was correct.)

After finishing the measurement, this is what Máté said.

It's not really accurate, because everybody has a different ell, and e.g.

Niki had to lower her hand to reach Eszti. (Actually he discovered the inaccuracy of measurement and he voiced it.)

When we attempted to determine the width of the classroom in ell, five children were not needed. This fact also shows how much Máté was right; because the measurement revealed that fathom was twice as much as ell, which is not really the case. From the point of view of measurement it did not really matter whether children were familiar with the relationship between ell and fathom or not, because it might have been a rather complicated for them and as a matter of fact it is not part of the curriculum. Our aim in this case was that the children could remember the relationship between measurements of unit and numbers by gaining experience.

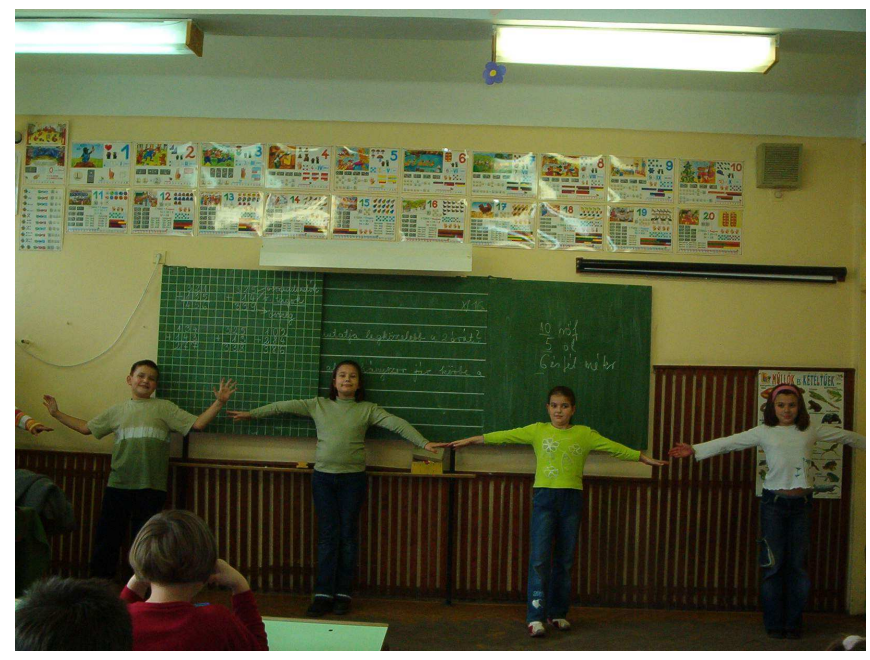

Picture 2

As it can be seen in Picture 2. If Pisti had stretched his arms properly, then fewer than five children would do to determine the width of the classroom.

Csaba: As a matter of fact how much is one fathom? Is it $190 \mathrm{~cm}$ ? (He is a clever boy, but normally asks a question when he knows the 


$$
\text { "tarcsi" - 2007/8/10 - 11:53 - page } 138 \text { - \#20 }
$$

answer. At this point he just wanted to point out the inaccuracy of measurement.)

$\mathrm{T}$ : How wide do you think this classroom is in meters? Will it be more or less than ell?

Some of them thought it was more and some them thought it was less. This is all the more interesting because children had measured the length of the classroom with measuring-rod several times, but this time it did not occur to them and did not recall it, only guessed.

$\mathrm{T}$ : It was five fathoms, how many metres will it be?

Children: About ten, Others' guess is eight or nine.

At earlier measurement the length of the classroom was found to be nine metres, but this time what they had in mind was that fathom is about twice as much as metre.

We put the measured values in fathom, metre and yard on the blackboard and tried to find out what they could deduce from them.

Eszter: I deduce the length of the classroom. (Eszter mixes up length and width)

Tamás: It can be determined by division, as a fathom equals to two ells.

This comes from the inaccurate measurement, but according to the data measured by them above statement is correct.

Csaba: We can calculate from it how much fathom is. (Csaba again raised the length of fathom, because he knew it for sure.)

We had to be more specific about the question whereas children were aware of the relationship between number and unit of measurement, but during the other lessons it was too unambiguously formulated to them, and this what they expected again.

$\mathrm{T}$ : Which has the biggest number?

Ági Kovács: The ell has the biggest number, because it is the smallest.

Tamás: Fathom has the smallest number because fathom is the biggest.

Children: The smaller the unit of measurement the bigger the number is.

They chant it in choir because during ordinary classes they do so sometimes without understanding what they are saying.

Csaba: The bigger the unit of measurement the bigger the number - but the other children are correcting that the smaller. (Normally Csaba 


$$
\text { "tarcsi" - 2007/8/10 - 11:53 - page } 139-\# 21
$$

does not make mistakes but verbally sometimes he is muddled, but he is familiar with numbers.)

Tamás: If we measured the classroom in millimetre, it would be about $6.500 \mathrm{~mm}$. (Tamás always likes to show off with his knowledge.)

We estimate the length of the classroom in ell, metre and fathom, but they still are not quite aware of the sizes, as they say one ell more than as many metres it is. Together we agreed on 13 or 14 ells.

The result of the measurement was 13 ells.

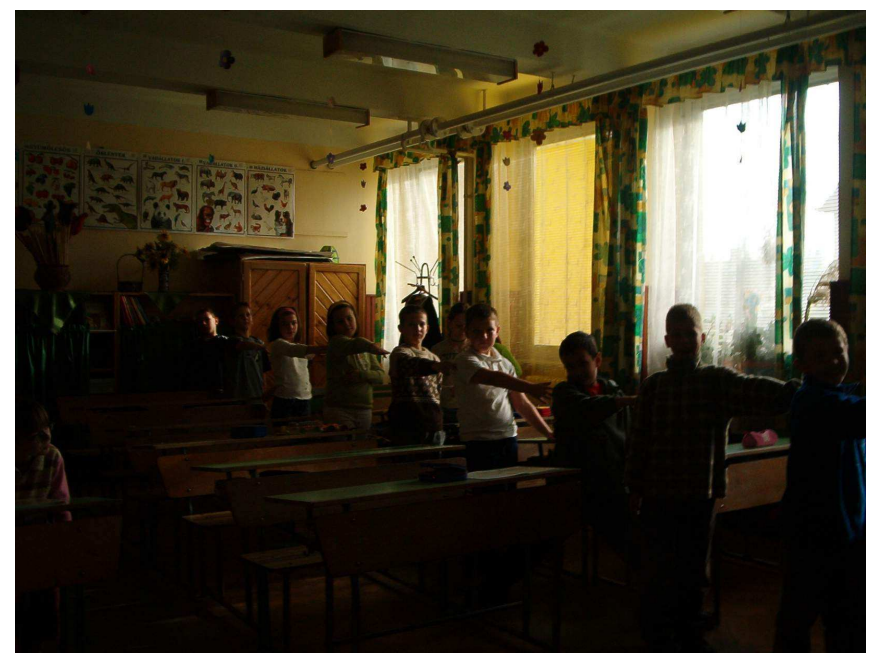

Picture 3

The length of the class was estimated at 6 to 10 fathoms (Six children stayed outside thus it is six fathoms.) Then it was also estimated in metre, their estimation was 7.5-8-9.5 metres. Actually it was nine and a half metre long. It had been measured earlier but not everybody remembered the value they measured, but it was also quite an achievement that everybody knew that the number in metre of the lengths of the classroom was bigger than that the width.

\subsubsection{The perimeter of rectangle}

Excerpts from lesson on $16^{\text {th }}$ November 2005.

$\mathrm{T}$ : How could we measure the perimeter of the classroom? 


$$
\text { "tarcsi" - 2007/8/10 - 11:53 - page } 140-\# 22
$$

Dávid: We could measure there, pointing at one side of the classroom, and also pointed at the opposite side, because it is the same over there, then he pointed at the adjacent side and said that: we could also measure it because the opposite side is the same. (David is very creative.)

$\mathrm{T}$ : Who can come up with other solutions?

Ági: We could stand forming a fathom.

The children stood by the walls at one arm's length from each other and they realised that 19 children (this was the number of children who took part in the session that day.) were not enough to encircle, thus the perimeter must be about 22 or 23 fathoms.
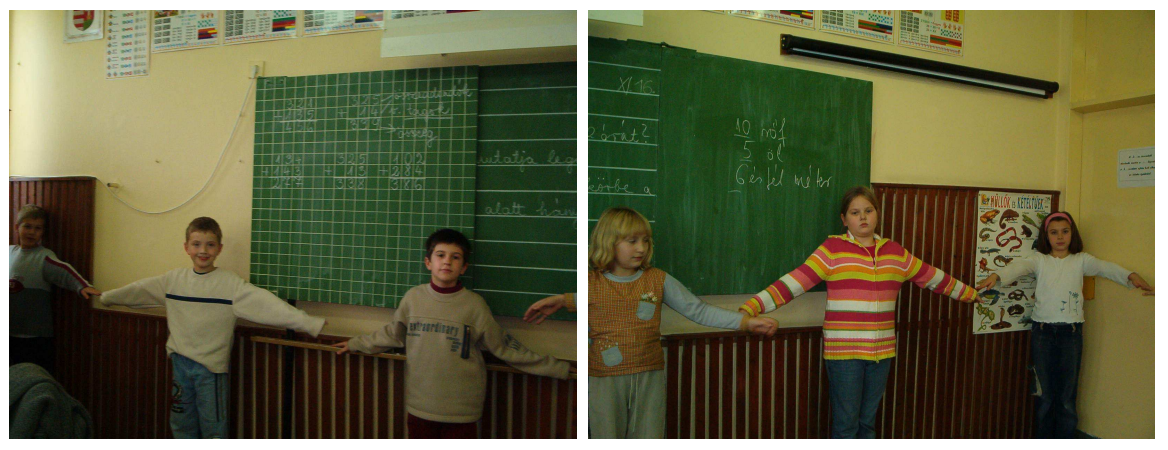

Picture 4
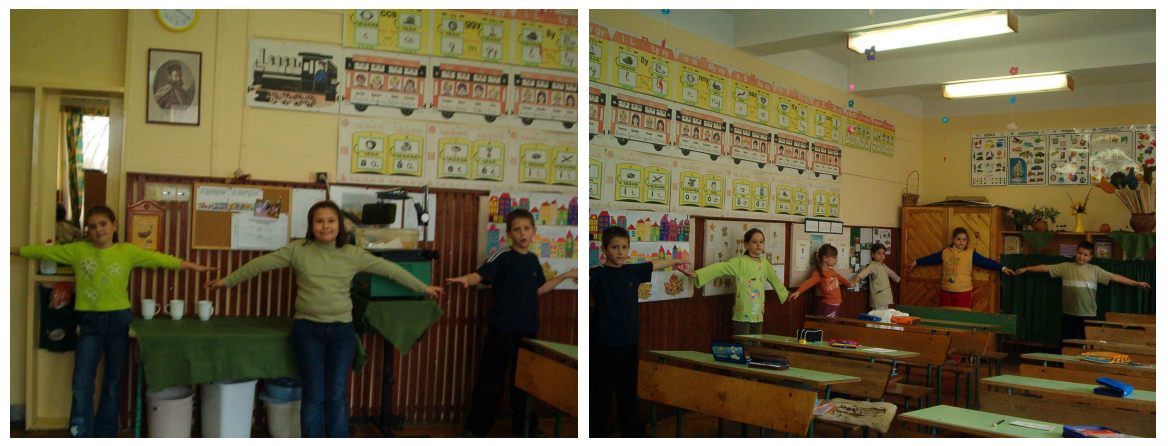

Picture 5

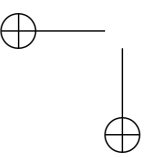




$$
\text { "tarcsi" - 2007/8/10 - 11:53 - page } 141-\# 23
$$

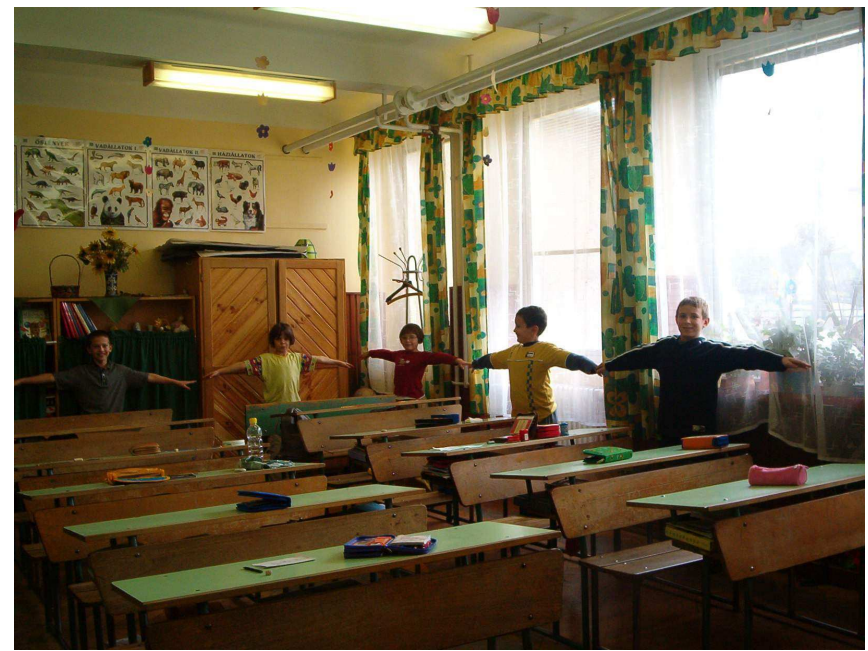

Picture 6

Kriszti: I could have been carried out in a way that aunty Margó (the teacher) takes photo of the children standing at the blackboard and then they will stop the gap. Then it could have been put together.

On one occasion we put this idea into practice and the result was 23 fathoms.

During the next session (on $21^{\text {st }}$ November 2005) we talked about forming rectangles and determine their perimeter.

Ági Kovács: It is possible to vary the forms of rectangles.

$\mathrm{T}$ : What do you mean by forms?

Ági Kovács: It is possible to pull them apart or to squeeze them.

Since in this case she had the rectangles made of straws in mind, the teacher told her that after squeezing it is not rectangles that we get.

Máté: What I mean by formation is that plus and minus... I take some from one side and add to the other, it will be the same... (Máté made use of the experience gained from drawing on quadratic grid paper, namely if a parallel pair of side of a rectangle is shorter by one quadratic grid and the other one is longer by one quadratic grid shorter, then the perimeter won't change.)

As we intended to consolidate the concept of the perimeter of the rectangle, we kept revising topics. 


$$
\text { "tarcsi" - 2007/8/10 - 11:53 - page } 142-\# 24
$$

David presents his idea raised earlier: I measure one side and the other one is the same - pointing at the opposite side, you don' have to measure all of them. Then after some hesitation he pointed at the side to be measured, then he also pointed at its opposite pair, however during the revision session he failed to express his ideas exactly.

Pisti: Let's suppose that one side is 10 metres and the other is 6 and a half. (We recommended to take six in order to count more easily.) Then $6+6=12$ and $10+10=20$ which makes 32 meter long perimeter.

$\mathrm{T}$ : Is there any other solution?

Tamás: What I want to say is that we have two shapes here, and we take from one side and we add it to the other, it won't be the same.

$\mathrm{T}$ : The rectangle will really be not the same but perimeter may be identical.

Máté: I would count in a way that I would measure of the opposite sides, and also one of the other sides then I'd add them. As we know the opposite sides are normally, moreover always the same and I'd add what we got as a result.

T: How many ways can we count it?

First we go round together: $10 \mathrm{~m}+6 \mathrm{~m}+10 \mathrm{~m}+6 \mathrm{~m}=32 \mathrm{~m}$.

Pisti says: $10 m+10 m+6 m+6 m$.

Csaba: So that we could measure the whole perimeter in one go.

Joci: $20 m+12 m$.

Kriszti: $6 m+6 m+10 m+10 m$ or $6 m+6 m+20 m$.

$\mathrm{T}$ : Last year you learned how to multiply. Could you use multiplication here?

Joci: Two times 10 and two times six.

Ági Kovács: Two times 16 metres.

Ági Barcza: $20 \mathrm{~m}$ plus two times $6 \mathrm{~m}$.

Tamás: Two times $10 \mathrm{~m}$ plus 12 metres.

Barnus: $12 \mathrm{~m}$ plus 20 metres.

Csaba: 8 times $4 \mathrm{~m}$.

$\mathrm{T}$ : It really makes 32 metres but it has nothing to do with the perimeter of the classroom.

The class considered Joci's solutions the best method of calculation. 


$$
\text { "tarcsi" - 2007/8/10 - 11:53 - page } 143-\# 25
$$

\section{Summarizing the results and conclusions}

- Children are quite familiar with the units of length, as it can be seen from the test, they don't mix them up with any other units of measurement.

- The children's estimations skills have improved a lot in using standard units. This improvement was rarely due to the fact that after every guessing they immediately wanted to measure the size of that particular thing if it happened to be in their surrounding, using a ruler, or measuring rod, or measuring tape depending on the size of the object.

- Shifting measurements was separated from practice, probably due to the mathematics classes in the morning. When the size of the same object had to be estimated in various units of measurements, 70 percent of the pupils did not make use of the relationship between number and the units of measurement, they tried to find out them separately as if they had not even heard of relationships between the units of measurements.

- They can use the ruler properly only a couple of them have difficulties in it.

- They are quite good at drawing broken lines and determining their length and there are hardly any pupils who have with directions.

- Children actually enjoyed coming up with several solutions to the determination of the perimeter of the rectangles. It happened than they were almost competing with each other when they were writing the solutions of this kind on the blackboard.

- They are able to recall the earlier tasks; some of them remember even their solutions and mistakes.

According to the above it can be said that our hypothesis was realistic which can also be seen into he results.

In our experiment we have come to the conclusion that in teaching length what we should put a greater emphasis on and follow up are as follows:

- Learners have quite a large amount of knowledge about the size of material objects and the relationships between them even before coming to school and we can rely on it in education.

- On radio, television, at home in the streets, at school and in fairy tales children are exposed to several terms which refer to the size, position, characteristics of objects and also their relationships to each other. In this way they pick up several geometrical terms, although several times they are not quite 


$$
\text { "tarcsi" - 2007/8/10 - 11:53 - page } 144-\# 26
$$

familiar with their meaning or might have misconceptions about them. At school it is up to the teacher to make learners understand the right content of the geometric concepts acquired earlier.

- In designing course material aimed at improving learners measurement skills, the concept of geometric quantity should be established, and we can rely on this knowledge in teaching the concept of number, the characteristics of operations with numbers, and all these things should be closely related to the teaching of shapes.

- It is also important for the pupils to become familiar with various instruments of measurements and develops skills to use them.

- In acquiring measurement skills cross-curricular aspects should also be taken into consideration.

- To improve estimation kills cannot be a temporary task; it has particularly great importance in everyday life, e.g. in estimating distance on the motorway.

\section{References}

[1] Hans Freudenthal, Didactical Phenomenology of Mathematical Structures, D. Reidel Publishing Company, Dortrecht, 1983.

[2] L. S. Vigotsky, Thought and Language, Trezor Kiadó, Budapest, 2000.

[3] Jean Piaget, Bärbel Inhelder, La psychologie de l'enfant, Presses Universitaires de France, Paris, 1966.

[4] Jean Piaget, La psychologie de l'intelligence, Armand Colin, Paris, 1967.

[5] Szendrei Julianna, Do You Think It's the Same? Dialogues on Mathematics Education, Typotex Kiadó, Budapest, 2005 (in Hungarian).

[6] C. Neményi Eszter, Geometry and Measurement, ELTE TOFK, Budapest, 1999 (in Hungarian).

[7] John Holt, How Children Fail, Gondolat Kiadó, 1991.

[8] Christopher Danielson, Perimeter in the Curriculum, For the Learning of Mathematics 25 (March 2005).

[9] Hajós György, First Concepts of Geometry, Tankönyvkiadó, Budapest, 1966 (in Hungarian).

[10] A. M. Piskalo, Геометрия в I-IV классах (Проблемы формирования геометрических представлений у младших школьников), Просвещение, Москва, 1968.

[11] George Pólya, Mathematical discovery: on understanding, learning, and teaching problem solving dicovering, John Wiley and Sons, New York, London, 1965.

[12] Ambrus András, Bevezetés a matematika didaktikába (Introduction into Didactics of Mathematic), ELTE Eötvös Kiadó, 1995 (in Hungarian). 
"tarcsi" - 2007/8/10 - 11:53 - page $145-\# 27$

MARGIT TARCSI

FERENC KÖLCSEY REFORMED TEACHER TRAINING COLLEGE

DEBRECEN

HUNGARY

E-mail: tarcsim@kfrtkf.hu

(Received November, 2006) 